\title{
Lordoplasty: report on early results with a new technique for the treatment of vertebral compression fractures to restore the lordosis
}

\author{
Rene Orler · Lars H. Frauchiger · Uta Lange · \\ Paul F. Heini
}

Received: 22 August 2005/ Revised: 14 March 2006/ Accepted: 26 March 2006/ Published online: 25 May 2006

(C) Springer-Verlag 2006

\begin{abstract}
Cement augmentation using PMMA cement is known as an efficient treatment for osteoporotic vertebral compression fractures with a rapid release of pain in most patients and prevention of an ongoing kyphotic deformity of the vertebrae treated. However, after a vertebroplasty there is no chance to restore vertebral height. Using the technique of kyphoplasty a certain restoration of vertebral body height can be achieved. But there is a limitation of recovery due to loss of correction when deflating the kyphoplastic ballon and before injecting the cement. In addition, the instruments used are quite expensive. Lordoplasty is another technique to restore kyphosis by indirect fracture reduction as it is used with an internal fixateur. The fractured and the adjacent vertebrae are instrumented with bone cannulas bipediculary and the adjacent vertebrae are augmentated with cement. After curing of the cement the fractured vertebra is reduced by applying a lordotic moment via the cannulas. While maintaining the pretension the fractured vertebra is reinforced. We performed a prospective trial of 26 patients with a lordoplastic procedure. There was a pain relief of about $87 \%$ and a significant decrease in VAS value from 7.3 to 1.9. Due to lordoplasty there was a significant and permanent correction in vertebral and segmental kyphotic angle about $15.2^{\circ}$ and $10.0^{\circ}$, respectively and also a significant restoration in anterior and mid vertebral height. Lordoplasty is a minimal invasive technique to restore
\end{abstract}

R. Orler $\cdot$ L. H. Frauchiger $\cdot$ U. Lange $\cdot$ P. F. Heini $(\bowtie)$ Department of Orthopaedic Surgery,

Inselspital, Bern, Switzerland

e-mail: paul.heini@insel.ch vertebral body height. An immediate relief of pain is achieved in most patients. The procedure is safe and cost effective.

Keywords Lordoplasty - Vertebral compression fractures $\cdot$ Osteoporosis $\cdot$ Cement augmentation

\section{Introduction}

Vertebral compression fractures (VCF) are frequent and constitute a common and often debilitating feature of osteoporosis. The incidence of vertebral compression fractures rises with increasing age $[25,29]$. Due to increasing elderly population the treatment of vertebral compression fractures becomes more and more important $[5,15,23,33,34,36]$. The lifetime risk of a clinically diagnosed vertebral compression fracture is about $15 \%$ in white women [7].

The treatment of vertebral compression fractures related to osteoporosis has been changed during the last 10 years: cement augmentation with a vertebroplasty stabilizes the fractured vertebra and also offers an immediate relief from pain in most patients [17, 24, 31].

Vertebroplasty has gained popularity during the past years for the treatment of osteoporotic compression fractures. Several reports document its usefulness in addressing pain and preventing of further collapse and preservation of posture. Rapid regression of pain has been found in $80-90 \%$ of treated patients with a long-lasting effect at a similar rate [5, 9, 19-21, 32]. Despite the high success with vertebroplasty, it does not address the associated spinal misalignment as it freezes the deformity. The spinal deformity leads to an increase in kyphosis and consequently to pulmonary 

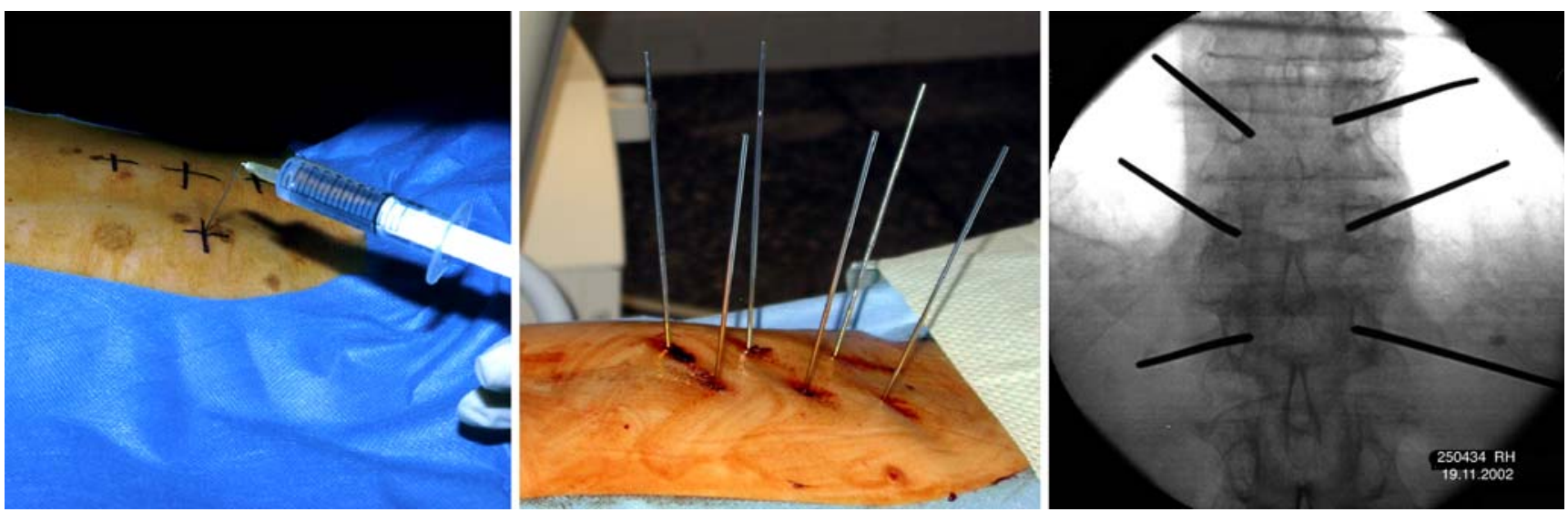

Fig. 1 Application of local anesthesia

Fig. 2-3 Bipedicular placement of $K$-wires with $C$ arm in ap view via stab incision
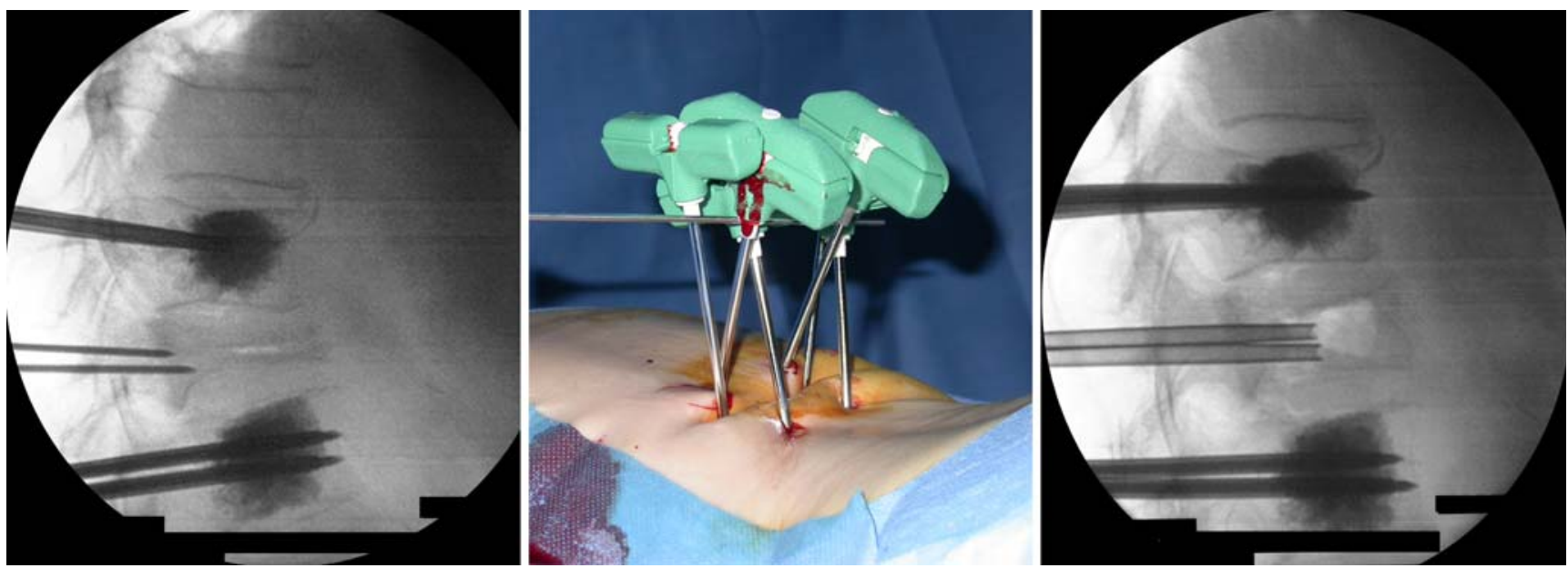

Fig. 4 Vertebroplasty of adjacent vertebrae, trochars slightly advanced

Fig. 5 Cannulas transconnected with a lordotic moment

Fig. 6 Lordotic moment applied on the fractured vertebra

and gastrointestinal problems [35]. There is also an increased risk of further osteoporotic fractures of the adjacent vertebrae after a first vertebral fracture [10, $22,26]$. The restoration of the height of the vertebral body and the lordosis of the segment cannot be sufficiently achieved using vertebroplasty $[3,13,30]$. One way to restore the height and the lordosis by reducing the fractured vertebra is by performing a kyphoplasty since it is known that a loss of lordosis encourages further vertebral compression fractures due to the overloading of the anterior column of the spine. However, the restoration of the kyphotic vertebra remains limited up to $6-9^{\circ}$ due to a loss of reduction when removing the inflatable bone temps and before performing the cement augmentation during the Kyphoplasty procedure [18].
Lordoplasty is a minimally invasive technique to restore the vertebral body's height and stabilize it using PMMA cement in this position.

\section{Patients and methods}

From October 2002 to September 2004, 36 patients $(11 \mathrm{~m} / 25 \mathrm{f})$ were treated with a lordoplasty for osteoporotic VCF in our institution. We performed a prospective non-randomized study on these patients. Inclusion criteria were compression fractures type A1 and A2 with a kyphotic angle of $>15^{\circ}$, persistent pain leading to hospitalization or immobilization for more than 3 weeks. 


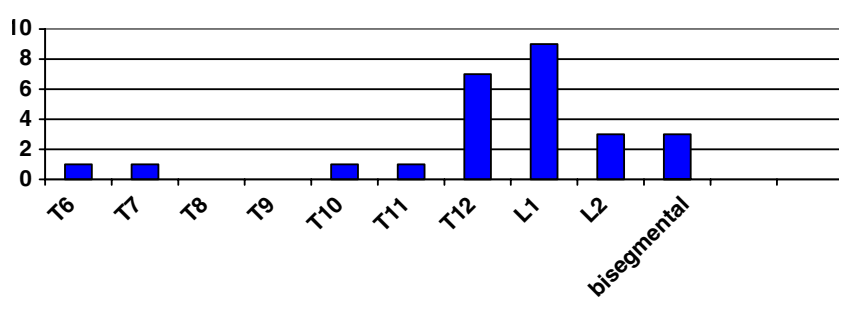

Fig. 7 Levels of treated vertebrae

To investigate the clinical course all the patients had to fill in a visual analog scale (VAS) ranged from 0-10 preoperatively, after 8 weeks and at the follow up examination at least 10 months postoperatively.

In addition we performed plan $\mathrm{x}$-rays relating to fractured part of the spine in the ap and lateral view preoperatively, 8 weeks postoperatively and at the follow up examination. The following data were obtained concerning the fractured vertebra: vertebral kyphotic angle, segmental kypotic angle and the vertebral body's height.

For the statistical evaluation of the results we used the programme SPSS for Windows (SPSS Inc., Chicago, Illinois, USA), version 12.0. Mean value and standard deviation were calculated for all values. Significance was calculated using the Wilcoxon and Mann-Whitney test. The significance level was taken as $P<0.05$ for all values.

\section{Surgical technique}

The principle of the surgical procedure is based on the indirect fracture reduction as it is used with internal fixation and relays on the principle of ligamentotaxis. The adjacent vertebrae are therefore instrumented with the filling cannulas bipedicularly together with the fractured one.

The patient is in a prone position in hyperextension on a radiolucent operation table. The procedure is preferably done in general anesthesia since the closed reduction and application of a lordotic moment while performing the procedure remain painful for the patient. In addition to this the vital signs can be monitored better using general anesthesia. Lordoplasty can also be performed under local anesthesia but the topics mentioned above have to be taken into account (Fig. 1). First the reduction due to the prone position is documented using a C-arm in lateral view. After stab incision, $\mathrm{K}$-wires of $2 \mathrm{~mm}$ in diameter are placed into both pedicles while using C-arm in ap view (Figs. 2, 3). When attaining the medial border of the pedicle the $\mathrm{C}$-arm is changed to a lateral view to check that the tips of the K-wires are just in front of the posterior wall of the vertebral body. Then bone biopsy needles (TrapLok $^{\mathrm{TM}}$ Bone Marrow Biopsy Needle, InterV-MD Tech, Gainesville, USA), sized 8 ga are placed within the middle of the vertebral body. After removal of the $\mathrm{K}$-wires a vertebroplasty of the adjacent vertebrae is performed using PMMA cement controlled with a $\mathrm{C}$-arm in a lateral view. The surgical technique follows a strict procedure [1]. The cement is only injected at an adapted viscosity $[4,27]$. It is important to realize that the trocar needs to be inserted, which adds a further $1 \mathrm{cc}$ of cement. Without the trocar the cannula will kink. After the placement of the trocar the cannulas are advanced about $5 \mathrm{~mm}$ to be completely set in the cement (Fig. 4).

When the cement has cured, the fractured vertebra is reduced by applying a lordotic moment via the cannulas. The cannulas are held in place either with a pointed reduction forceps (Weber type) or by transconnecting the cannulas with a blunt trocar (Fig. 5). This allows to apply and maintain a lordotic moment on the fractured vertebra (Fig. 6). The amount of force applied depends on the elasticity of the cannula-trocar system used. (This is part of an ongoing study). It is possible to additionally perform a kyphoplasty procedure in selected cases in order to improve fracture reduction. While the pretension is maintained the fractured vertebra is reinforced. When the cement is cured the cannulas are released and removed.

\section{Results}

About 26/36 patients [6 males/20 females, 71.5 (5686) years] received a follow-up examination on average 15.1 months (10-24) after the operation. Three patients died during the follow-up for reasons not related to the surgical treatment, one was lost to follow-up due to removal, two patients have had an open
Table 1 Vertebral and segmental kyphotic angles (deg)

\begin{tabular}{lllllll}
\hline & Pre OP & $\begin{array}{l}\text { Eight } \\
\text { weeks }\end{array}$ & $\begin{array}{l}\text { Sign. pre-8 } \\
\text { weeks }\end{array}$ & FU & $\begin{array}{l}\text { Sign. } \\
\text { pre-FU }\end{array}$ & $\begin{array}{l}\text { Sign. 8 } \\
\text { weeks-FU }\end{array}$ \\
\hline $\begin{array}{l}\text { Vertebral } \\
\text { kyphotic angle }\end{array}$ & $24.1 \pm 7.7$ & $8.9 \pm 5.8$ & $P<0.001$ & $11.8 \pm 6.4$ & $P<0.001$ & $P<0.023$ \\
$\begin{array}{c}\text { Segmental } \\
\text { kyphotic angle }\end{array}$ & $15.4 \pm 9.5$ & $5.5 \pm 10.0$ & $P<0.001$ & $8.3 \pm 10.2$ & $P=0.001$ & $P=0.049$ \\
\hline
\end{tabular}


Table 2 Vertebral height (in $\mathrm{mm}$ )

\begin{tabular}{lllllll}
\hline & Pre OP & Eight weeks & Sign. pre-8 weeks & FU & Sign. pre-FU & Sign. 8 weeks-FU \\
\hline Ant. border & $10.9 \pm 6.3$ & $21.9 \pm 5.0$ & $P<0.001$ & $20.8 \pm 4.3$ & $P<0.001$ & $P=0.221$ \\
Mid- vertebra & $14.1 \pm 6.4$ & $22.9 \pm 3.9$ & $P<0.001$ & $21.1 \pm 3.9$ & $P<0.001$ & $P=0.028$ \\
Post. border & $25.7 \pm 7.7$ & $27.5 \pm 4.2$ & $P=0.125$ & $29.0 \pm 4.4$ & $P<0.020$ & $P=0.205$ \\
\hline
\end{tabular}

Table 3 Worst case scenario: minimal values

\begin{tabular}{lcclccc}
\hline & Pre OP & Eight weeks & Sign. pre-8 weeks & FU & Sign. pre-FU & Sign. 8 weeks-FU \\
\hline Vertebral kyphotic angle & $19.8 \pm 10.8$ & $6.2 \pm 7.2$ & $P<0.001$ & $9.0 \pm 7.6$ & $P<0.001$ & $P=0.003$ \\
Segmental kyphotic angle & $10.0 \pm 12.5$ & $1.5 \pm 10.8$ & $P<0.001$ & $2.7 \pm 12.7$ & $P<0.001$ & $P=0.666$ \\
Ant. border & $8.9 \pm 6.7$ & $19.8 \pm 6.0$ & $P<0.001$ & $19.2 \pm 5.1$ & $P<0.001$ & $P=0.619$ \\
Mid-vertebra & $12.0 \pm 6.9$ & $21.4 \pm 4.5$ & $P<0.001$ & $19.8 \pm 4.2$ & $P<0.001$ & $P=0.003$ \\
Post. border & $22.5 \pm 9.0$ & $25.4 \pm 5.4$ & $P=0.005$ & $26.9 \pm 5.4$ & $P<0.001$ & $P=0.050$ \\
\hline
\end{tabular}

Table 4 Worst case scenario: maximum values

\begin{tabular}{lllllll}
\hline & Pre OP & Eight weeks & Sign. pre-8 weeks & FU & Sign. pre-FU & Sign. 8 weeks-FU \\
\hline Vertebral kyphotic angle & $27.8 \pm 10.1$ & $11.1 \pm 7.0$ & $P<0.001$ & $14.1 \pm 7.9$ & $P<0.001$ & $P=0.002$ \\
Segmental kyphotic angle & $22.2 \pm 13.9$ & $14.9 \pm 17.9$ & $P<0.001$ & $15.5 \pm 15.0$ & $P<0.001$ & $P=0.902$ \\
Ant. border & $13.8 \pm 9.3$ & $23.4 \pm 5.3$ & $P<0.001$ & $22.8 \pm 5.4$ & $P<0.001$ & $P=0.619$ \\
Mid-vertebra & $16.6 \pm 8.0$ & $24.4 \pm 4.6$ & $P<0.001$ & $22.3 \pm 4.2$ & $P<0.001$ & $P=0.001$ \\
Post. border & $28.0 \pm 8.8$ & $28.8 \pm 4.7$ & $P=0.616$ & $31.2 \pm 6.1$ & $P=0.003$ & $P=0.005$ \\
\hline
\end{tabular}

reduction-internal stabilization due to a persistent segmental instability and four patients resisted the follow up examination. The lordoplasties were mainly performed on fractures of the thoracolumbar junction.
In three patients we performed lordoplasties at two levels (Fig. 7).

Eight patients were operated with local anesthesia and 18 patients with general anesthesia. The operating
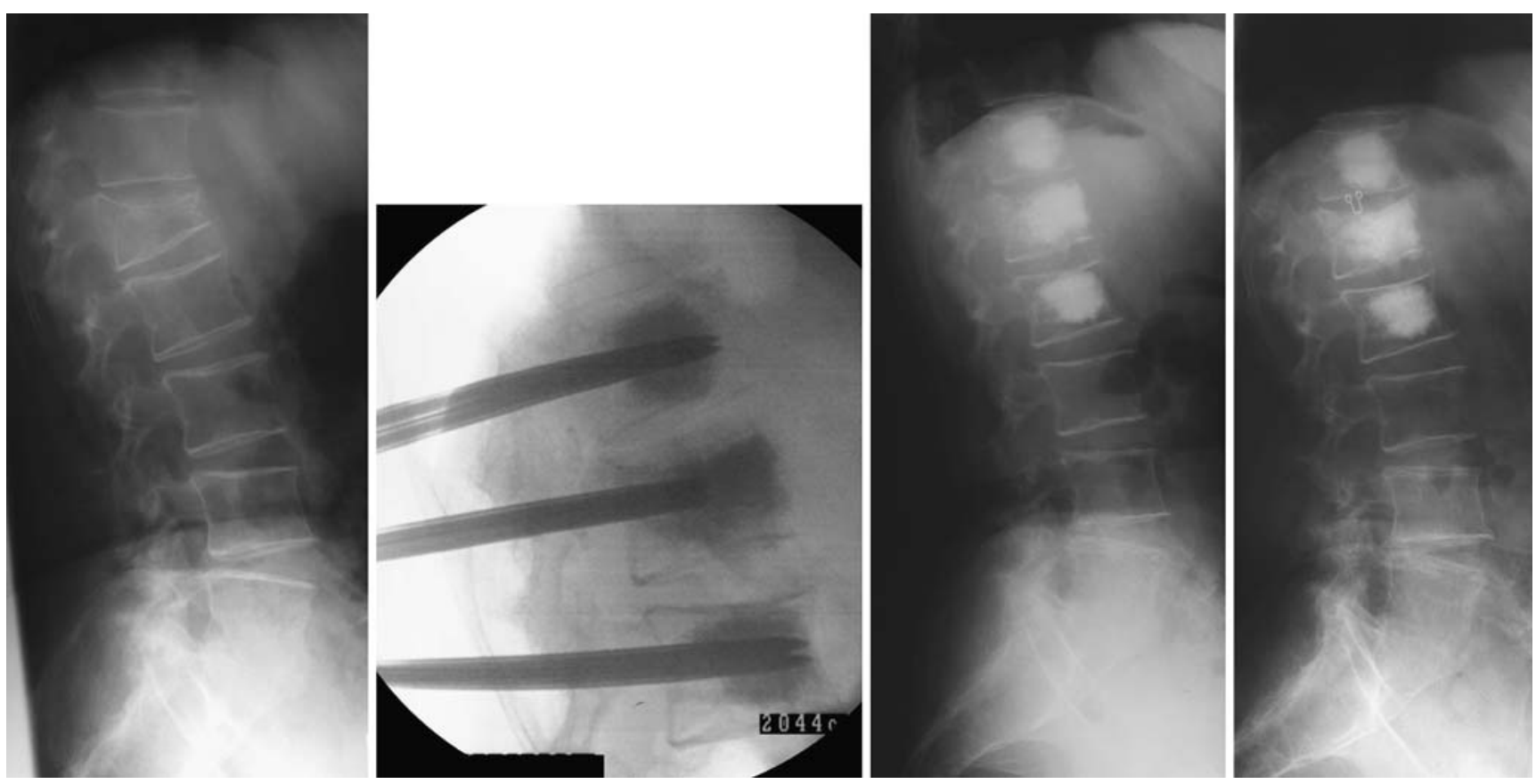

Fig. 8 A 68-year-old female patient: lordoplasty performed on a vertebral compression fracture of L1 
Fig. 9 A 70-year-old female patient: lordoplasty performed on a vertebral compression fracture of T12: cement leakage into cranial disc (no clinical symptoms)
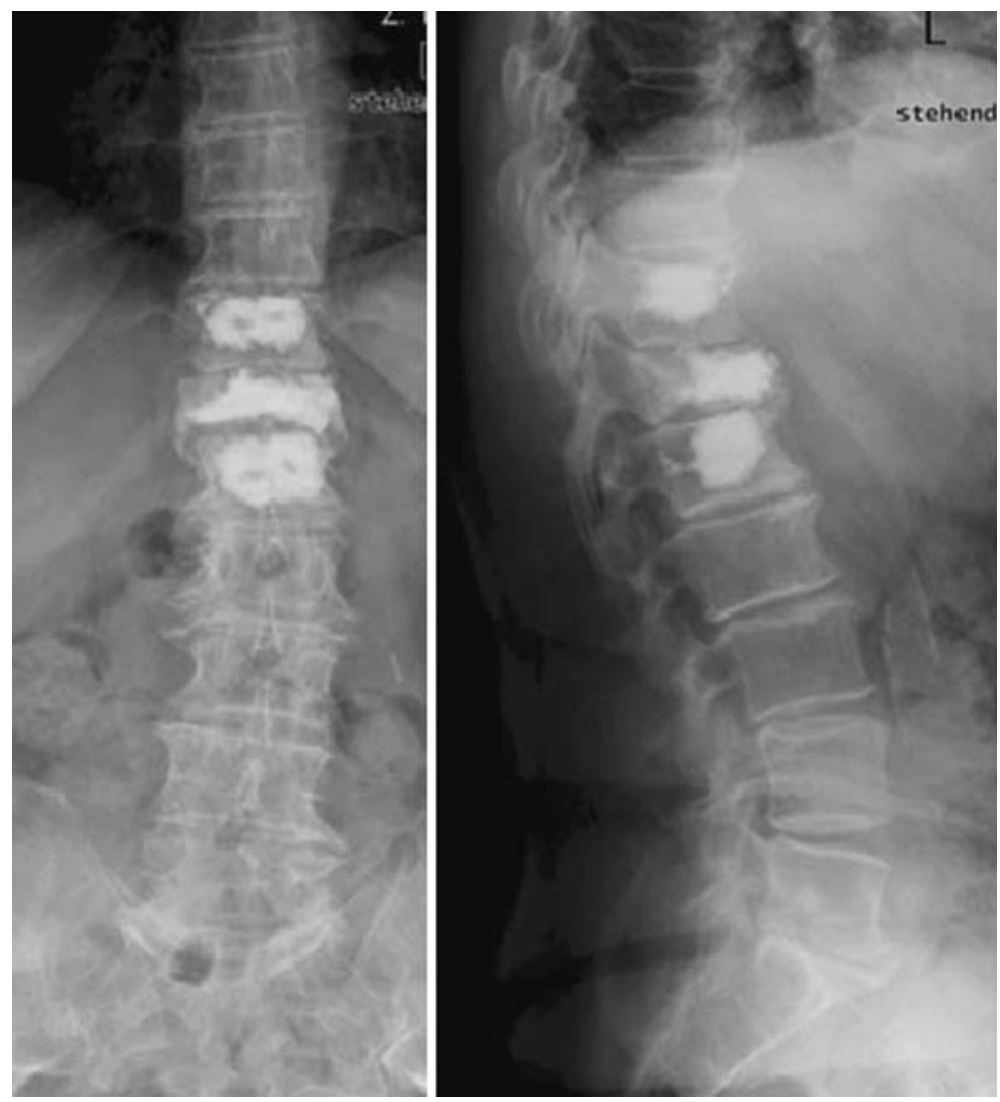

time was about 61 (40-90) min on an average, and mean duration of hospital stay was about $3(1-8)$ days. Prior to operation the patients had a history of pain for about 48 (2-360) days. Due to surgical procedure there was a relief of pain of about $87 \%$ and a significant decrease in VAS value from 7.3 preoperatively to 2.4 $(P<0.001) 8$ weeks later and to even $1.9(P<0.001)$ after 16 months.

After lordoplasty there was a significant and permanent correction in vertebral and segmental kyphotic angle up to follow up examination of about $15.2^{\circ}$ $(P<0.001)$ and $10.0^{\circ}(P<0.001)$, (Table 1$)$. Due to resting in a prone position on the operation table there was a significant amount of spontaneous restoration in vertebral and segmental lordosis of about $8.2 \pm 5.9^{\circ}$ $(P=0.008)$ and $15.3 \pm 12.4^{\circ}(P=0.008)$. After lordoplasty there was a further significant increase in vertebral lordosis of about $5.9 \pm 5.9^{\circ}(P=0.024)$.

Due to the lordoplastic procedure there was a significant restoration of the anterior vertebral border of about $11.0 \pm 5.7 \mathrm{~mm}(P<0.001)$ and the mid vertebral height of about $8.8 \pm 5.6 \mathrm{~mm}(P<0.001)$. Since osteoporotic fracture results mainly in kyphotic deformity or collapse of the mid vertebral height the restoration of the posterior vertebral border was not significant $(1.8 \pm 5.5 \mathrm{~mm})$, Table 2 .
We also performed a worst case scenario statistics, since we lost 10/36 patients during the follow-up period due to the reasons mentioned above. Therefore, we replaced both minimal and maximum values whenever the measurement was incomplete in follow up and performed statistical calculation again. There was no significant difference between the calculation for the 26 patients with follow-up examination and the worst and the best case scenarios except for the restoration of the posterior vertebral border, Tables 3 and 4.

The following complications were seen: one patient complained of passing radicular symptoms most probably caused by foraminal nerve root compression during the reduction maneuver. In one patient we had to change from local to general anesthesia because the patient experienced excessive pain. One patient presented with a fracture of an adjacent vertebra 4 weeks after lordoplasty, this vertebra was augmented by a vertebroplasty without any further trouble. Two patients developed a segmental instability of the adjacent segments and had to be therefore treated with an internal stabilization and spondylodesis.

There was no major complication during the application of the cement, such as pulmonary embolism or leakage into the spinal canal. 


\section{Discussion}

Osteoporotic VCFs are the major cause for back pain in the elderly. Even though only about one-third of all fractures comes to clinical attention [6], the VCFs have major aftereffects on the patients' physical function, quality of life and survival. Due to the increasing age of our population, the rate of osteoporotic fractures is expected to triple over the next 30 years [38].

The objective target in treating VCFs is a relief of pain and the restoration of spinal function with a minimal invasive therapy. The ideal treatment should result in an immediate relief of fracture-related pain and a durable restoration of vertebral body height and correction of angular deformity. Various publications show the benefit of kyphoplasty in pain reduction and restoration of the lordosis [13, 17, 24, 28, 31].

Both vertebroplasty and kyphoplasty lead to immediate pain relief because of the broken vertebra is stabilized and further deformity prevented [3, 9, 17]. Characteristic complications such as cement extrusion and pulmonary embolism are less likely to appear in kyphoplasty due to lower pressure when injecting the cement [18]. In addition, a restoration of height and correction of kyphosis is achieved by filling the kyphoplasty ballon. There are reports of relative restoration of vertebral body height between 0 and $90 \%$ and correction in kyphotic angle up to $9.5^{\circ}[8,11,14,28,37$, $40,41]$. At the same time there is a device related problem with the amount of restoration: when filling the kyphoplasty ballon a satisfying reduction is achieved in many patients. However, the resulting reduction after cementing is about $25 \%$ lower due to the partial collapse after balloon deflation [18].

"Vertebral body stenting" is a combination of kyphoplasty and the use of stents to prevent loss of correction after deflating the balloon [12]. No clinical data using this procedure are presented until now.

With lordoplasty we attained a better initial reduction $\left(15.2^{\circ}\right.$ and $10.0^{\circ}$ in vertebral and segmental kyphotic angle) (Fig. 8) and had less reduction loss during follow-up compared to kyphoplasty [3, 13, 30]. In addition we did not observe any loss of reduction during the lordoplasty procedure as is the case in kyphoplasty [18].

Recent biomechanical investigations give evidence for an increased fracture risk of the vertebral bodies adjacent to augmented levels [2]. In a clinical series, Grados et al. [16] reported on 34 new VCFs after a mean follow-up of 48 months in 13 of 25 patients treated with vertebroplasty $(52 \%)$. Another study with a two-year follow-up reported a $12.4 \%$ rate of new fractures, two-thirds of which were directly adjacent to the previously treated level [39]. With lordoplasty there is an augmentation of the vertebrae cranial and caudal adjacent to the fracture. So we expect a reduced risk of fractures in adjacent vertebral bodies. In our series there was only one patient with a fracture of the cranial adjacent vertebra during follow-up. This fracture was treated with a vertebroplasty uneventfully.

We also observed cases of minor leakage during vertebroplasty (Fig. 9), as several authors reported [19, 28, 30]. However, these patients did not show any evidence of clinical signs. So we think that the risk of additional minor cement leakage during cement augmentation of the adjacent vertebrae is justified due to the benefit from the loroplastic procedure and prophylactic stabilization of these vertebrae. Last but not the least, the cost of the material is one-third compared to kyphoplasty.

There are some limitations concerning the study design: This is an early prospective, non-randomized examination of a new surgical procedure. So we had more extensive inclusion criteria to get results at an early point of time and from as many patients as possible. This led to a wide range in lordotic angle. In spite of trying we did not manage to follow-up all the patients due to the reasons mentioned above. Therefore, further investigation on patients treated with a lordoplasty is requested. We are already planning for such a study.

\section{Conclusion}

Lordoplasty is a minimal invasive technique to restore spinal function by reconstruction of vertebral body height and correction of angular deformity using PMMA cement. A restoration up to $13^{\circ}$ can be obtained using this technique. There is an immediate relief in pain in most patients. The procedure is safe and cost-effective. Further investigation of this new technique is required.

\section{Reference}

1. Berlemann U, Heini PF (2002) Perkutane Zementierungstechniken zur Behandlung osteoporotischer Wirbelkörpersinterungen. Unfallchirurg 105(1):2-8

2. Berlemann U, Ferguson SJ, Nolte L-P, Heini PF (2002) Adjacent vertebral failure after vertebroplasty. A biomechanical investigation. J Bone Joint Surg Br 84:748-752

3. Berlemann U, Franz T, Orler R, Heini PF (2004) Kyphoplasty for the treatment of osteoporotic vertebral fractures: a prospective non-randomized study. Eur Spine J 13(6):496-501

4. Bohner M, Gasser B, Baround G, Heini P (2003) Theoretical and experimental model to describe the injection of a polymethylmetacrylate cement into a popous structure. Biomaterials 24(16):2721-2730 
5. Cook DJ, Guyatt GH, Adachi JD, Clifton J et al (1993) Quality of life issues in women with vertebral fractures due to osteoporosis. Arthritis Rheum 36(6):750-756

6. Cooper C, Atkinson EJ, Jacobsen SJ, O'Fallon WM, Melton III LJ (1993) Population based study of survival after osteoporotic fractures. Am J Epidemiol 137(9):1001-1005

7. Dennison E, Cooper C (2000) Epidemiology of osteoporotic fractures. Horm Res 54(S1):58-63

8. Dudensey S, Lieberman IH, Reinhardt MK, Hussein M (2002) Kyphoplasty in the treatment of osteolytic vertebral compression fractures as a result of multiple myeloma. J Clin Oncol 20:2382-2387

9. Einhorn TA (2000) Vertebroplasty: an opportunity to do something really good for patients. Spine 25:1051-1052

10. Espallargues M, Sampietro-Colom L, Estrada MD, Solà M et al (2001) Identifying bone-mass-related risk factors for fracture to guide bone densitometry measurements: a systematic review of the literature. Osteoporos Int 12:811-822

11. Fourney DR, Schomer DF, Nader R, Chlan-Fourney J et al (2003) Percutaneous vertebroplasty and kyphoplasty for painful vertebral body fractures in cancer patients. J Neurosurg 98(S1):21-30

12. Fürderer S, Anders M, Schwindling B, Salick M et al (2002) Vertebral body stenditing: a method for repositioning and augmenting vertebral compression fractures. Orthopäde 31:356-361

13. Garfin SR, Yuan HA, Reiley MA (2001) Kyphoplasty and vertebroplasty for the treatment of painful osteoporotic compression fractures. Spine 26(14):1511-1515

14. Garfin SR, Yuan HA, Reiley MA (2001) New technologies in spine: kyphoplasty and vertebroplasty for teh treatment of painful osteoporotic compression fractures. Spine 26:15111515

15. Gold DT (1996) The clinical impact of vertebral fractures: quality of life in women with osteoporosis. Bone 18(S3):185S-189S

16. Grados F, Depriester C, Cayrolle G, Hardy N, Deramond H, Fardellone P (2000) Long-term observations of vertebral osteoporotic fractures treated by percutaneous vertebroplasty. Rheumatology 29(12):1410-1414

17. Heini PF (2005) The current treatment-a survey of osteoporotic fracture treatment. Osteoporotic spine fractures: the surgeon's perspective. Osteoporos Int 16(S1):S85-S92

18. Heini PF, Orler R (2004) Kyphoplasty for treatment of osteoporotic vertebral fractures. Eur Spine J 13:184-192

19. Heini PF, Orler R (2004) Vertebroplasty in severe osteoporosis. Technique and experience with multi-segment injection. Orthopäde 33(1):22-30

20. Heini PF, Walchi B, Berlemann U (2000) Percutaneous trasnpedicular vertebroplasty with PMMA: operative technique and early results. A prospective study for the treatment of osteoporotic compression fractures. Eur Spine J 9(5):445-450

21. Hodler J, Peck D, Gilula LA (2003) Midterm outcome after vertebroplasty: predictive value of technical and patient-related factors. Radiology 227(3):662-668

22. Johnell O, Kanis JA, Odèn A, Sernbo I et al (2004) Fracture risk following an osteoporotic fracture. Osteoporos Int 15:175-179
23. Kado DM, Browner WS, Palermo L, Nevitt MC, Genant HK, Cummings SR (1999) Vertebral fractures and mortality in older women: a prospective study. Study of osteoporotic fractures research group. Arch Intern Med 159(11):12151220

24. Kallmes DF, Jensen ME (2003) Percutaneous vertebroplasty. Radiology 229(1):27-36

25. Kanis JA, Pitt FA (2005) Epidemiology of osteoporosis. Bone 13:S7-S15

26. Klotzbuecher CM, Ross PD, LAndsman PB, Abbott III TA, Berger M (2000) Patients with prior fractures have an increased risk of future fractures: a summary of the literature and statistical synthesis. J Bone Min Res 15(4):721-739

27. Krebs J, Ferguson SJ, Bohner M, Baround G, Steffen T, Heini PF (2005) Clinical measurements of cement injection pressure during vertebroplasty. Spine 30(5):E118-E122

28. Ledlie JT, Renfro M (2003) Balloon kyphoplasty: one-year outcomes in vertebral body height restoration, chronic pain and activity levels. J Neurosurg 98(S1):36-42

29. Lee YL, Yip KM (1996) The osteoporotic spine. Clin Orthop 323:91-96

30. Lieberman IH, Dudensey S, Reinhardt MK, Bell G (2001) Initial outcome and efficacy of "kyphoplasty" in the treatment of painful osteoporotic vertebral compression fractures. Spine 26:1631-1638

31. Peh WCG, Gilula LA, Peck DD (2002) Percutaneous vertebroplasty for severe oteoporotic vertebral body compression fractures. Radiology 223(1):121-126

32. Perez-Higueras A, Alvarez L, Rossi RE, Quinones D, AlAssir I (2002) Percutaneous vertebroplasty: long-term clinical and radiological outcome. Neuroradiology 44(11):950954

33. Riggs BL, Melton III LJ (1995) The worldwide problem of osteoporosis: insights afforded by epidemiology. Bone 17(S5):505S-511S

34. Ryan PJ, Blake G, Herd R, Fogelman I (1994) A clinical profile of back pain and disability in patients with spinal osteoporosis. Bone 15:27-30

35. Schlaich C, Minne HW, Bruckner T, Wagner G et al (1998) Reduced pulmonary function in patients with spinal osteoporotic fractures. Osteoporos Int 8(3)

36. Silverman SL (1992) The clinical consequences of vertebral compression fracture. Bone 13(S2):S27-S31

37. Theodorou DJ, Theodorou SJ, Duncan TD, Garfin SR, Wong WH (2002) Percutaneous balloon kyphoplasty for the correction of spinal deformity in painful vertebral compression fractures. Clin Imaging 26(1):1-5

38. Truumees E (2001) Osteoporosis. Spine 26(8):930-932

39. Uppin AA, Hirsch JA, Centenera LV, Pfieler BA, Pazianos AG, Choi IS (2003) Occurrence of new vertebral body fractures after percutaneous vertebroplasty in patients with osteoporosis. Radiology 226:119-124

40. Weisskopf M, Herlein S, Birnbaum K (2003) Kyphoplasty - a new minimally invasive treatment for repositioning and stabilising vertebral bodies. Z Orthop Ihre Grenzgeb 141:406411

41. Wong W, Riley MA, Garfin S (2000) Vertebroplasty/kyphoplasty. J Womens Imaging 2:117-124 